\title{
NOÇÕES DOS FUTUROS PROFISSIONAIS DA QUÍMICA. EIXO I: LIBERDADES E DEMANDAS DA PESQUISA
}

\author{
Ricardo Strack* e José Claudio Del Pino
}

Instituto de Química, Universidade Federal do Rio Grande do Sul, Av. Bento Gonçalves, 9500, 91501-970 Porto Alegre - RS, Brasil

Recebido em 11/6/10; aceito em 21/2/11; publicado na web em 15/4/11

\begin{abstract}
NOTIONS OF FUTURE CHEMISTRY PROFESSIONALS. AXIS I: RESEARCH LIBERTIES AND DEMANDS. During the schooling process, images are constructed about research and researcher activities. Based on that, a questionnaire has been structured based on three thematic axes that tend to represent some of the discussions about the translations that integrate the scientific activity collectively: freedom and demands from research, academia as a mediator and science disclosure. The objective of the instrument was to map some notions from entrants to the graduation course in Chemistry in the metropolitan region of Porto Alegre about what, based on the contributions by Bruno Latour, was called vascularizations of research.
\end{abstract}

Keywords: chemist formation; conceptions; research.

\section{INTRODUÇÃO}

Na 25ำ Reunião Anual da SBQ (RASBQ), em 2002, foram realizadas atividades visando discutir a formação dos futuros profissionais da química: o workshop "Um olhar sobre a pós-graduação em Química no Brasil" e o simpósio "Eixos mobilizadores em Química" são alguns exemplos. Como resultados destes eventos foram identificados seis eixos mobilizadores divulgados no artigo Eixos mobilizadores em química. ${ }^{1}$ Neste os autores defendem, entre outras, uma aproximação pró-ativa da academia com a atividade econômica.

A etapa seguinte desta série de eventos foi o simpósio "A Formação do Químico", ${ }^{2}$ que ocorreu na 26a RASBQ. O objetivo principal deste simpósio foi discutir a formação dos profissionais de Química em nível de graduação e pós-graduação e as suas repercussões no ensino. ${ }^{3}$ No resumo do referido simpósio Galembeck ${ }^{3}$ argumenta que os problemas na formação dos químicos dizem menos à sua formação em Química e mais da sua inserção tanto no seu ambiente, como na sua profissão e no seu plano de vida. As mudanças necessárias envolvem mais as atitudes (de professores e alunos) e o clima intelectual e profissional nos departamentos de Química do que alterações curriculares pontuais. ${ }^{3}$

Ao encontro desta posição, Araújo e colaboradores ${ }^{4}$ argumentam que "para a comunidade acadêmica, explorar comercialmente as atividades de pesquisa requer uma grande mudança na forma de pensar e trabalhar". Acrescente-se que, além disso, há o envolvimento de tensões de ordem social e política, uma vez que, retomando as pautas das discussões do Fórum Mundial Ciência e Democracia, "todo conhecimento, inclusive a ciência, é a herança comum da humanidade". ${ }^{5}$ Uma herança comum enquanto conhecimentos, mas enquanto bens de consumo?

Uma vez que os químicos são e serão visitados por estas opiniões diversas, o posicionamento de um futuro profissional da química quanto a estas na sua atividade profissional é um pré-requisito para esboçarmos um quadro das noções articuladas por estes. Neste sentido, como argumenta Latour: ${ }^{6}$

*e-mail: ricstrack@yahoo.com.br talvez possamos esboçar as diferentes preocupações que todos os pesquisadores terão de alimentar ao mesmo tempo caso queiram ser bons cientistas (p. 117).

\section{O questionário VVP}

O conjunto do referencial latourniano fornece novas perspectivas interpretativas aos instrumentos de coleta de dados de visões sobre a natureza da ciência (VNC). A primeira reinterpretação pautada por este referencial é a substituição da noção de 'ciência' pela 'pesquisa' por incluir nesta última o caráter controverso das translações sóciopolítico-econômicas que participam das atividades dos pesquisadores. ${ }^{6,7}$ Neste ponto pode se considerar a existência de um instrumento a respeito das visões sobre a natureza da pesquisa.

No entanto, Latour ${ }^{6}$ problematiza inclusive o conceito de 'natureza' por estar associado a um suposto 'mundo exterior' inserido nas dicotomias da modernidade: dentro (Mente), fora (Natureza), em cima (Deus) e em baixo (Sociedade). A partir das preocupações relacionadas tanto à formação quanto à escolha profissional na carreira ligada à Química, surgiu a necessidade de pensar um instrumento visando evidenciar, na forma de um questionário, as visões sobre vascularizações da pesquisa por parte dos calouros de cursos de Química. ${ }^{8}$

Um instrumento de coleta de dados a respeito das visões sobre vascularizações da pesquisa (VVP) deve buscar evidenciar as noções sobre os processos que integram esta ao coletivo, metaforicamente denominadas por Latour de "fluxo sanguíneo da ciência". ${ }^{6}$ Tal instrumento $^{9,10}$ foi constituído por conjuntos de questões visando mapear alguns aspectos e imagens que fazem parte das visões dos futuros profissionais da Química sobre as vascularizações da pesquisa no coletivo.

Objetiva-se levantar as concepções sobre pesquisa que os calouros trazem ao entrarem nas Instituições; afinal, ao se ter conhecimento destas noções, torna-se possível esboçar como (e quais) noções podem ser enriquecidas através de ações em cursos de formação profissional na área de Química. A intenção é mostrar justamente que estes ingressantes adentram aos cursos superiores de Química com 'concepções prévias'. Não estamos discutindo, aqui, as origens destas concepções nem se pretende discutir a construção ou reconstrução 
destas ao longo do tempo. Isso será uma segunda etapa do trabalho, ainda em andamento.

Ressaltamos que a elucidação destas noções possibilita pensar em estratégias formativas voltadas a um perfil mais condizente com as demandas de formação de profissionais educados pela pesquisa, em função de que esta faculta o desenvolvimento de habilidades inerentes à atividade científico-acadêmica como, por exemplo, autonomia, iniciativa e pensamento crítico.

O instrumento foi respondido por 121 calouros dos cursos de graduação em Química da Região Metropolitana de Porto Alegre (UFRGS -26; PUCRS - 37; ULBRA - 41 e Unilasalle - 17 calouros). Para cada item das 14 questões existiam cinco graus de importância $(0,1,2,3$, 4) a serem atribuídos, com 0 representando a menor e 4 a maior. Após tabulação, os dados foram renormalizados a partir do escalonamento das pontuações, onde 0 receberia pontuação $-2 ; 1,-1 ; 2,0 ; 3,1$ e o grau 4 receberia pontuação 2 (Quadro 1). A soma das pontuações em cada item possibilitaria um perfil sintético para cada questão.

Quadro 1. Escalonamento das pontuações

\begin{tabular}{cc}
\hline Peso atribuído pelo respondente & Valor associado para quantificação \\
\hline 0 & -2 \\
1 & -1 \\
2 & 0 \\
3 & 1 \\
4 & 2 \\
\hline
\end{tabular}

A aplicação do questionário envolveu o consentimento dos professores das disciplinas de começo de curso dos cursos de Química das respectivas instituições, os quais cederam cerca de $30 \mathrm{~min}$ das suas aulas para que os alunos respondessem as questões. Não era permitido que os questionários fossem levados para posterior entrega respondidos, tendo em vista que gostaríamos de levantar suas noções mobilizadas in loco, sem os recursos de pesquisa na web, por exemplo.

\section{As liberdades e demandas na pesquisa}

No início de 2009 realizou-se em Belém (PA) o Fórum Social Mundial (FSM) e, em conjunto, o Fórum Mundial Ciência e Democracia que tinha, em linhas gerais, as propostas de uma "participação democrática da ciência" podendo ser estas sintetizadas neste recorte dos questionamentos e das diretrizes propostas: ${ }^{5}$

Apoiamos os regimes que garantem e promovem os bens públicos e comuns e outros sistemas de recompensa da inovação que não envolvem a criação de monopólios de conhecimento e geração de lucros.

A ciência e a tecnologia estão implicadas nas crises que assolam o mundo nos dias de hoje - a crise econômica, a ecológica, a energética e as relacionadas à segurança alimentar, à democracia, à guerra e ao militarismo. É necessário aprofundar nossa compreensão a respeito de como a ciência e a tecnologia são parte tanto das causas quanto das possibilidades de superação dessas crises.

É necessário reconhecer que os valores das comunidades científicas são moldados por processos históricos e culturais. A autonomia e a responsabilidade social dos pesquisadores, bem como o caráter público e universal da ciência, precisam ser promovidos, porém levando em conta as diversidades sociais e culturais do tempo presente. $[\ldots]$

Devem ser promovidas iniciativas visando o envolvimento informado de cidadãos nos processos de tomada de decisões relativas às políticas científicas e tecnológicas em todos os níveis, internacional, nacional e local.

É imprescindivel promover a participação social e o empoderamento da população a fim de exercer o controle democrático sobre as políticas científicas e tecnológicas.

De forma mais enfática, a declaração pós-FSM denuncia: ${ }^{5}$

É absolutamente necessário mudar a situação de hoje, em que os interesses do mercado, o lucro das empresas, a cultura consumista e os usos militares são os principais elementos que determinam os rumos da pesquisa científica e tecnológica. ${ }^{11}$

Obviamente a pluralidade de opiniões também existe nesta temática, como pode ser observado por posicionamentos como o evidenciado no artigo de Silva ${ }^{12}$ ao criticar a dependência direta com demandas sociais; afinal "é a independência nos processos de investigação e de debate que garante o desenvolvimento da produção, da transmissão e da aplicação do saber".

Com base nestas discussões convém questionar como estudantes de cursos superiores de química veem estas demandas. Em 1997, Stein e McRobbie ${ }^{13}$ publicaram um trabalho no qual apresentaram algumas concepções de ciência de alunos ao longo do processo de escolarização. Um dos posicionamentos enfatiza o papel que movimentos cíveis desempenham nas mudanças das condutas de pesquisas:

"A mudança científica é influenciada pelos direitos humanos e direitos dos animais em testes, por exemplo, testes nucleares" [tradução livre].

Analisando as respostas dos calouros do curso de Química da Universidade Federal do Rio Grande do Sul pode-se inferir que esta tendência de valorizar a participação de movimentos cíveis também se faz presente no item Planejamento da pesquisa (Figura 1) conforme pontuação na opção Organizações da Sociedade Civil (OSC). Mas a participação em movimentos da sociedade não implica, necessariamente, na exclusão dos outros interesses, como fica evidenciado pelo item Empresas Públicas (EP), seguido pelos interesses governamentais (Gov). A importância atribuída ao item Pesquisador indica uma noção de pesquisa em cujo planejamento há uma relativa proeminência deste, mesma tendência apresentada pelos calouros da Pontifícia Universidade Católica do Rio Grande do Sul, ao mesmo tempo em que há uma menor pontuação atribuída às OSC e, inversamente, um maior papel às empresas públicas (EP). Os itens que mais destoam no planejamento de uma pesquisa entre ambos grupos são os papéis atribuídos às instâncias governamental e às Empresas Privadas Estrangeiras (EPE).

Questão 1: Graus de importância atribuídos aos diversos interesses que podem tomar parte no planejamento de uma pesquisa na área de química.

A mesma tendência de proeminência do papel do pesquisador foi encontrada nas respostas dos calouros da Unilasalle, seguida pelos Conselhos e Empresas Públicas, enquanto que, na Ulbra, as Empresas Públicas apresentam mesma pontuação relativa que o item Pesquisador, seguindo-se, em ordem de importância, Conselhos de ética na pesquisa (Cons) e Organizações da Sociedade Civil (OSC). 


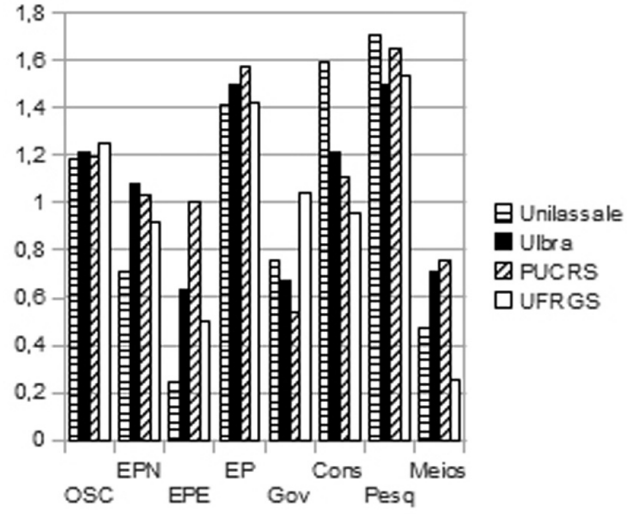

Figura 1. OSC: Organizações da Sociedade Civil, EPN: Empresas Privadas Nacionais, EPE: Empresas Privadas Estrangeiras, EP: Empresas Públicas, Gov: Governo, Cons: Conselhos de ética na pesquisa, Pesq: o próprio pesquisador, Meios: meios de comunicação

No item execução da pesquisa (Figura 2), com relação aos calouros da UFRGS, as pontuações semelhantes frente aos itens anteriores são um indicativo de uma noção de pesquisa na qual os partícipes do planejar e do executar estão relacionados, embora certos itens possam apresentar diferenças relativas. Um exemplo foi a redução acentuada da importância atribuída às OSC na execução da pesquisa frente ao planejamento, seguida pela redução menos significativa do papel associado aos Meios de Comunicação (Meios) e um leve fortalecimento da importância atribuída aos interesses das Empresas Privadas Nacionais (EPN), Empresas Privadas Estrangeiras (EPE) e das Empresas Públicas (EP). De modo relativamente diferente, os calouros da PUCRS mantêm a totalidade do perfil da Questão 1 com relação à Questão 2 (Figura 2), com um relativo enfraquecimento do papel do pesquisador e dos meios de comunicação, seguidos pelo fortalecimento da instância governamental. Objetivamente, pode-se inferir que, aos calouros da PUCRS, o planejar e o executar de uma pesquisa não são tarefas claramente distinguíveis.

Tanto para os respondentes da Ulbra quanto da Unilasalle, o papel atribuído às Empresas Públicas e às Empresas Privadas Estrangeiras apresenta incremento, embora este seja mais marcante com relação ao item EPE do último grupo citado, o que ressalta que a semelhança entre as noções de planejar e executar uma pesquisa não são tão patentes nos respondentes da Unilasalle.

\section{Questão 2: Graus de importância atribuídos aos diversos} interesses que podem tomar parte na execução de uma pesquisa na área de Química.

Embora não exista uma coincidência completa de todas as respostas sobre as pontuações dos interesses que podem tomar parte tanto no planejamento quanto na execução de uma pesquisa, há uma tendência comum aos quatro grupos de respondentes: a presença destacada do papel de duas instâncias que podem ser sintetizadas no binômio Empresa Pública-Pesquisador (EP+Pesq).

O perfil apresentado pelos respondentes calouros da UFRGS (Figura 3) no item financiamento da pesquisa (Questão 3) indica a noção de que as fontes de recursos são provenientes basicamente das Empresas Públicas e do Governo, seguidas em menor grau pelas Empresas Privadas Nacionais e Empresas Privadas Estrangeiras (EPE). Há a compreensão de que o Pesquisador não financia a pesquisa com o seu próprio dinheiro. Um perfil semelhante surge com relação aos calouros da PUCRS, no entanto, com um papel significativamente maior para os Organismos Internacionais (OI)

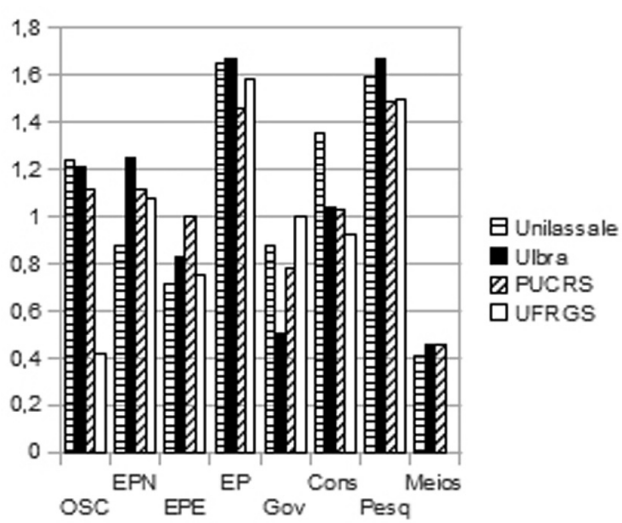

Figura 2. OSC: Organizações da Sociedade Civil, EPN: Empresas Privadas Nacionais, EPE: Empresas Privadas Estrangeiras, EP: Empresas Públicas, Gov: Governo, Cons: Conselhos de ética na pesquisa, Pesq: próprio pesquisador, Meios: meios de comunicação

e menor para o Governo.

Tanto os calouros da Unilasalle quanto da Ulbra atribuem a maior ênfase às Empresas Públicas como principal fonte de financiamento de uma pesquisa, embora isso seja mais destacado nas respostas deste último grupo do que da Unilasalle.

Questão 3: Graus de importância atribuídos aos investimentos das diversas fontes de financiamentos de uma pesquisa na área de Química.

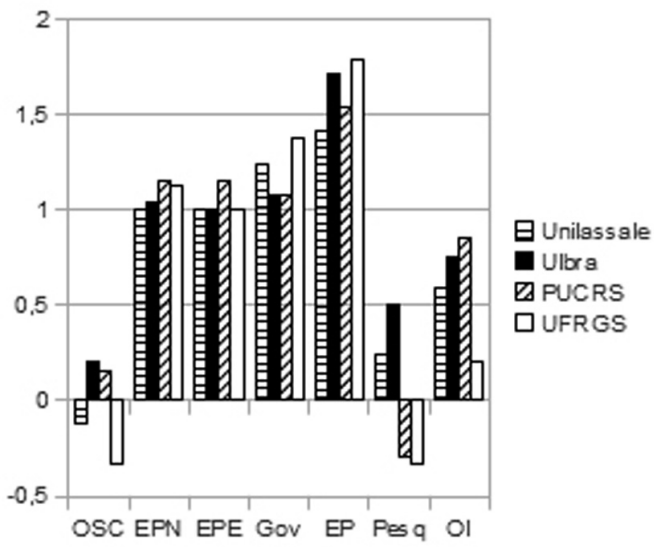

Figura 3. OSC: Organizações da Sociedade Civil, EPN: Empresas Privadas Nacionais, EPE: Empresas Privadas Estrangeiras, EP: Empresas Públicas, Gov: Governo, Pesq: próprio pesquisador, OI: Organismos Internacionais

Neste contexto no qual a pesquisa se apresenta como uma instância na qual estão articulados aspectos de planejamento, execução e financiamento, pergunta-se pelos resultados objetivos que emergem da sua prática: os inventos tecnocientíficos (Figura 4). A prioridade da sua propriedade (Questão 4) é um forte indicativo da noção dos interesses majoritários que conduzem estes não humanos ${ }^{6,14}$ nos meandros das redes vasculares que caracterizam a pesquisa no contexto latourniano.

A Quebra de Patente (Quebr), embora não seja um item de atribuição de propriedade em si mesmo, objetiva mapear a concepção dos respondentes relativa à possibilidade de se sobrepor o interesse público sobre as prioridades de propriedade justamente apresentadas por estes. 
Questão 4: Graus de prioridade atribuídos à propriedade de um invento tecnocientífico (direito como proprietário).

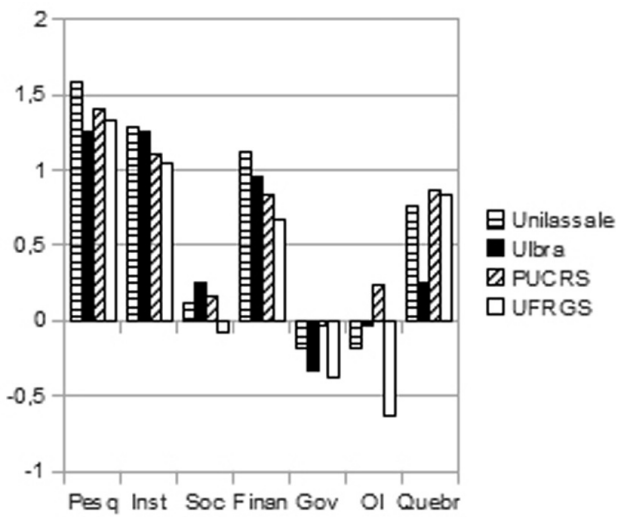

Figura 4. Pesq: pesquisador, Inst: Instituição, Soc: sociedade em geral, Finan: aqueles que financiaram, Gov: Governo, OI: Organismos Internacionais, Quebr: Quebra de patente se tiver uso social de grande importância

Para o conjunto dos quatro grupos de respondentes, a quebra de patente sempre ficou abaixo, no mínimo, das prioridades atribuídas ao Pesquisador e à Instituição onde foi realizada a pesquisa (Inst). No caso dos calouros da UFRGS, o item Quebr superou inclusive a posição de quem Financiou a pesquisa (Finan), tendência semelhante apresentada pelos respondentes da PUCRS. Nos casos da Unilasalle e da Ulbra, a possibilidade de quebra de patente se apresentou como item abaixo de Pesquisador, Instituição e quem Financia, sendo que o item Quebr, no caso da Ulbra, apresenta a menor importância no conjunto dos grupos.

A partir da análise do item Organismos Internacionais (OI) na questão do financiamento (Questão 3) parece que, à medida que participem (ou não) do financiamento de uma pesquisa, há uma menor (ou maior) aversão à noção de que estes tenham prioridade sobre a propriedade de um invento tecnocientífico (Questão 4) como pode ser percebido mais claramente com relação aos respondentes da PUCRS. Parece haver uma relação de proporcionalidade direta entre financiamento e propriedade, no que tange a este item (Figura 5).

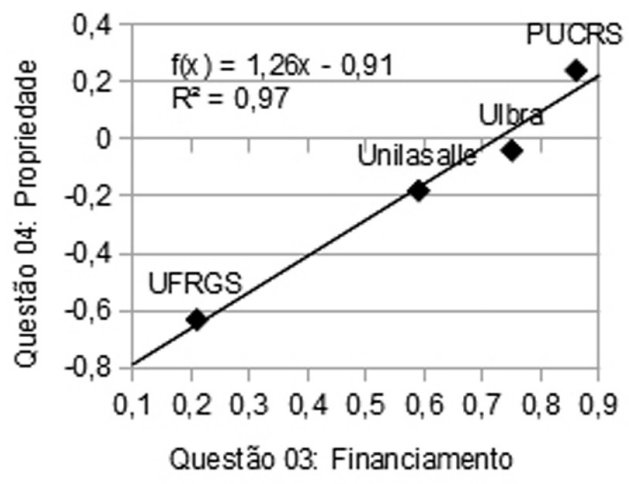

Figura 5.

É interessante observar que a relação entre financiamento e propriedade, já abarcada pelo item Financiadores da mesma questão (Questão 4), é corroborada por outro, qual seja, Organismos Internacionais (OI), o que nos faculta algumas reflexões sobre algumas não linearidades entre propriedade e financiamento. Seria de se esperar, a princípio, que essa tendência emergisse em outros itens, como Governo ou Pesquisador. Da mesma forma, o item Finan deveria destacar-se frente aos demais, supondo-se que os respondentes atrelem a propriedade somente ao financiamento.

Em primeiro lugar, o fato de a atribuição de propriedade com base no financiamento (item Finan) ficar como o terceiro item mais pontuado em todos os respondentes, a parte do item especial da quebra de patente, estando abaixo tanto do Pesquisador quanto da Instituição, indica a existência de motivos outros, que não o de financiamento, que justifiquem a prioridade destes dois itens sobre a propriedade de um invento tecnocientífico. Na ausência destes supostos 'motivos outros', é provável que a linearidade emergisse.

Um caso de especial interesse é a atribuição de prioridade ao pesquisador, uma vez que este ator, segundo os respondentes, é um dos que menos participa do financiamento da pesquisa. No entanto, é o que recebe maior pontuação nas respostas à Questão 4. O que isso indica? A existência de uma forma de reconhecimento não derivada diretamente da esfera de financiamento. Na obra $A$ Vida de Laboratório,${ }^{15}$ Latour propõe um modelo para o processo de credibilidade científica no qual as diferentes abordagens possíveis para se analisar a atividade dos cientistas, tanto epistemológicas quanto econômicas, por exemplo, estão unificadas nas fases de um ciclo único: o ciclo da credibilidade.

O pesquisador, o cientista, não é um mero ator econômico que teria suas atribuições apenas em função do capital financeiro investido em uma pesquisa. Há mais do que isso no processo de pesquisar: a instituição de um ciclo de crédito-credibilidade ${ }^{15}$ o qual

[...] torna possível a conversão entre dinheiro, dados, prestígio, referências, áreas dos problemas tratados, argumentos, artigos, etc. Ao contrário de vários estudos sobre a ciência, centrados sobre uma parcela específica do círculo, podemos dizer que cada uma dessas facetas é somente uma parte de um ciclo sem fim de investimento e de conversão. (p. 224)

Dito de outra forma, há uma atribuição não derivada diretamente da esfera de financiamento e talvez seja essa outra legitimidade/ autoridade que esteja subentendida nas respostas dos calouros. No entanto, como Latour nessa obra ${ }^{15}$ faz referência ao ciclo ligando-o mais ao papel dos artigos do que aos inventos tecnocientíficos, essa apropriação visando a sua expansão para o domínio da propriedade enquanto patente requer algumas elucidações maiores, principalmente as relacionadas especificamente à propriedade sobre as informações tecnocientíficas, incluídos aí os artigos os quais o modelo latourniano abrange mais claramente.

Em linhas gerais, ao se observar as pontuações quanto à propriedade de um invento tecnocientífico, a importância significativa atribuída ao pesquisador segue a tendência de focar a atividade de pesquisa sobre este, acrescida da emergência do papel institucional que surge como mais um moderador (ou talvez mediador) frente às outras instâncias. Neste conjunto, a possibilidade de quebra de patente chama especialmente a atenção. No conjunto dos itens até agora levantados, em todos os casos, a opção dos produtos tecnocientíficos serem propriedade intelectual de alguém não era apresentada. Até a questão 4, qualquer atribuição ou não da patente aos financiadores estava em aberto. A prioridade sobre um invento tecnocientífico é o ponto chave para esclarecer como os respondentes visualizam a confrontação de interesses e a presença do item Quebra de patente (Quebr) aponta na direção da função social do conhecimento químico. Com base nisto, cabe a pergunta: afinal de contas, qual a finalidade da pesquisa na área de Química? 
Questão 5: Graus de importância atribuídos às diversas finalidades da pesquisa na área de química.

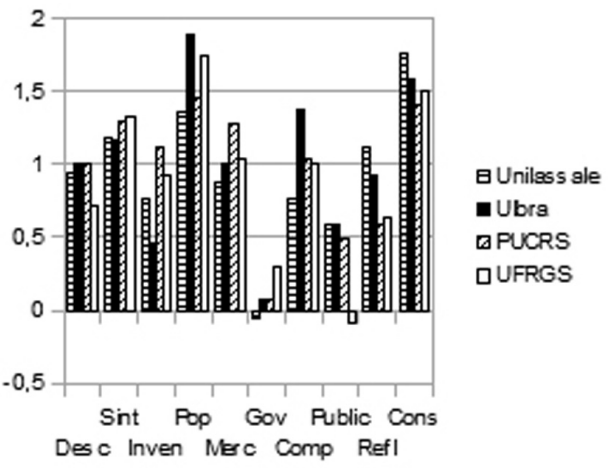

Figura 6. Desc: descobrir leis naturais, Sint: sintetizar substâncias, Inven: inventar coisas, Pop: atender às necessidades da população, Merc: atender aos interesses do mercado, Gov: atender aos interesses do governo, Comp: compreender o mundo, Public: publicar artigos, Refl: possibilitar reflexões sobre o ensino, Cons: construir conhecimento

Aos calouros da UFRGS, as respostas apontam, prioritariamente, na direção de atender às necessidades da população (Pop) e construir conhecimento (Cons) seguido de sintetizar substâncias (Sint). Comparando com os resultados da PUCRS, houve a mesma tendência, com o incremento dos relacionados ao mercado e redução dos itens Pop, Cons e Sint. De forma mais marcada, os itens 'Atender às necessidades da população' e 'Construir conhecimento' são reforçados pelos respondentes da ULBRA, minimizando o de sintetizar substâncias, retomando parte das noções dos grupos anteriores, mas com o acréscimo da noção de que, atendendo aos interesses da população, se constrói conhecimento e se compreende o mundo (Comp). De forma inversa, aos respondentes da Unilasalle, a predominância da construção de conhecimento é seguida pela de atendimento das necessidades da população.

A construção de conhecimento surge como um primeiro indicativo, no conjunto das questões analisadas até o momento, da imagem do papel desempenhado pela pesquisa em Química; enquanto um processo epistêmico, afinal, até agora, era visualizada mais prontamente a instituição dos produtos tecnocientíficos, mas não estava clara a função epistêmica: de forma sucinta e genérica pode-se dizer que, para a totalidade dos grupos, a concepção geral nesta questão é construir conhecimento atendendo as necessidades da população.

Neste contexto de pesquisa se pergunta pelos atributos de um dos seus principais atores, o pesquisador (Questão 6), uma vez que sua importância já havia sido evidenciada nas questões 1 (item Pesq) e 2 (item Pesq) e, tendo em vista o exposto até o momento, talvez seja a peça-chave na elucidação da imagem dos calouros sobre as liberdades e demandas na pesquisa química.

Questão 6: Graus de importância atribuídos aos diversos atributos de um pesquisador.

Aqui cabe uma ressalva importante. No cabeçalho da questão já havia a referência aos atributos de um pesquisador competente, o que implicou no fato de o item 'ser competente' ser redundante nas respostas. Infelizmente, tal redundância passou despercebida não só pelos avaliadores do questionário como pelos próprios autores, o que implica que a presença do item 'ser competente' acaba por não trazer um acréscimo à discussão já que a escolha estava induzida por este item no cabeçalho.

Observando os resultados, as respostas podem ser organizadas em dois grupos com importâncias relativas opostas: as atribuições

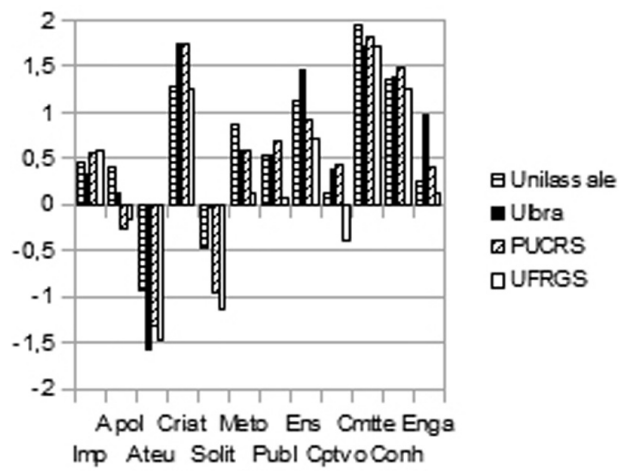

Figura 7. Imp: imparcial, Apol: apolítico, Ateu: ateu, Criat: criativo, Solit: solitário, Meto: seguir rigidamente as metologias das ciências, Publ: publicar artigos, Ens: saber ensinar, Cptvo: competitivo, Cmtte: competente, Conhe: ter muito conhecimento, Enga: socialmente engajado

de importância positiva como, por exemplo, ser criativo (Criat), ser competente (Cmtte) e ter conhecimento (Conh) e as atribuições de importância negativa, quais sejam, ser ateu (Ateu) e ser solitário (Solit). Ao olhar dos respondentes da UFRGS um pesquisador, neste conjunto, deve ser prioritariamente competente, seguido de ser criativo na mesma importância em que deve ter muito conhecimento, ao passo que não é importante que ele seja ateu ou solitário.

No âmbito dos calouros da PUCRS, os itens ser competente, criativo e ter muito conhecimento são manifestados da mesma forma, embora com pontuações maiores. Acrescente-se a emergência do papel das publicações e do ensino. Não é importante que o pesquisador seja ateu ou solitário, embora em um grau menor se comparado ao grupo anterior.

Aos calouros da ULBRA, a competência e a Criatividade despontam, seguidas pela irrelevância de ser ateu, pela importância de saber ensinar e de ter muito conhecimento.

Com relação aos respondentes da Unilasalle, a competência adquire uma importância ainda maior seguida, em menor intensidade, por ter muito conhecimento e ser criativo.

É interessante observar a existência de dois atributos necessários que se destacam como comuns pelos quatro grupos: criatividade e conhecimento. $\mathrm{O}$ atributo desnecessário, ser ateu, também recorrente em todos os grupos, completa as características genéricas de um pesquisador da área de Química, segundo o conjunto geral dos respondentes calouros.

A imagem comumente atribuída pelos alunos do Ensino Médio ao cientista como alguém solitário em seu laboratório ${ }^{16}$ destoa da noção apresentada aqui. Uma vez que os respondentes optaram por uma carreira ligada diretamente à atividade científica, é possível que sua escolha estivesse pautada por uma concepção menos estigmatizada. $\mathrm{O}$ item 'ser ateu' merece um comentário à parte. $\mathrm{O}$ ateísmo na ciência é um assunto particularmente interessante em meio às disputas extremistas entre criacionismo ${ }^{17,18}$ e teoria da evolução. Embora os calouros não deem importância ao fato do pesquisador ser ou não ateu, este é um aspecto chave na postura iconoclasta moderna, ${ }^{6,19}$ uma vez que se insere no conjunto das dicotomias fundantes do acordo modernista, conforme a crítica de Latour ${ }^{6}$ à crença ingênua na crença ingênua de outrem. ${ }^{20}$

A iconoclastia não despedaça um ídolo, mas destrói um modo de argumentar e de agir que era anátema para o iconoclasta. A única pessoa que está projetando seus sentimentos no ídolo é ele, o iconoclasta com um martelo, e não aqueles que por esse gesto devem ser libertados de seus grilhões. A única pessoa que acredita é ele, o combatente de todas as 
crenças. Por quê? Por que ele [...] acredita no sentimento de crença, um sentimento muito estranho, na verdade, que pode não existir em parte alguma, salvo na mente do iconoclasta (p. 310-311). ${ }^{6}$

A partir do mesmo autor podemos asseverar que, para além de uma questão psicológica, ${ }^{21}$ a oposição à postura religiosa, ou melhor, à iconoclastia moderna, está embebida em uma perspectiva políticoepistêmica já denunciada no livro Esperança de Pandora. ${ }^{6}$

A crença, a crença ingênua é a única maneira de que o iconoclasta dispõe pra entrar em contato, contato violento, com os outros - exatamente como os epistemologistas não tinham outro modo de contrastar Pasteur e Pouchet senão dizendo que o último acreditava e o primeiro sabia. A crença, entretanto, não é um estado psicológico, não é um modo de apreender declarações, mas um modo polêmico de relações (p. 311). ${ }^{6}$

\section{CONSIDERAÇÕES FINAIS}

Objetivamente, foi uma tendência voltada para a função social do conhecimento científico que emergiu no quadro geral das opiniões dos calouros: aparentemente a pesquisa, atendendo aos interesses da população, objetiva a construção de conhecimento num processo de mediação que engloba interesses mercadológicos e governamentais. A pergunta que se sucede é: uma vez que existem posicionamentos que demandam entre outras coisas aproximações pró-ativas com a atividade econômica e a formação de um profissional com perfil empreendedor, como se articulam os interesses na apropriação dos produtos resultantes da atividade de pesquisa? E o papel do pesquisador na pesquisa?

Em primeiro lugar, destaca-se o fato de que o papel central exercido na atividade de pesquisa cabe ao pesquisador, tanto no planejamento quanto nas decisões acerca da execução desta. $\mathrm{O}$ pesquisador não é somente mais um ator que teria suas atribuições apenas em função, por exemplo, do capital financeiro investido em uma pesquisa. Há mais do que isso no processo de pesquisar: a instituição de um ciclo de crédito-credibilidade ${ }^{15}$ que tem, na atribuição de propriedade, uma das etapas.

As prioridades atribuídas sobre a propriedade de um invento apresentados pelos respondentes podem supor um modelo no qual os dividendos são repartidos entre estes três agentes: o pesquisador, a instituição e quem financiou, na mesma concepção de divisão tripartite apresentada por Araújo e colaboradores. ${ }^{4}$ Ficam em aberto, para posteriores pesquisas e novas versões do questionário, esclarecimentos mais precisos sobre a partição dos dividendos decorrentes da pesquisa.

A questão do patenteamento e da propriedade sintetiza toda uma trajetória na qual os recursos, sejam informacionais, financeiros ou institucionais, são articulados pelo pesquisador. Araújo e colaboradores $^{4}$ representam esse processo de mobilização como um esquema cíclico, que pode ser interpretado como uma versão simplificada do ciclo de credibilidade de Latour.

Em linhas gerais, ao se observar a tendência geral quanto à propriedade de um invento tecnocientífico, a significativa importância atribuída ao pesquisador segue a tendência de focar a atividade de pesquisa sobre este, acrescida da emergência do papel institucional que surge como mais um moderador (ou talvez mediador) frente às outras instâncias. O papel desempenhado pelo pesquisador neste processo é central, no qual certas concepções acerca da atividade científica são deslocadas.

Se a Ciência possui certeza, frieza, distanciamento, objetividade, isenção e necessidade, a Pesquisa parece apresentar to- das as características opostas: ela é incerta, aberta, às vezes com problemas insignificantes como dinheiro, instrumentos e know-how, incapaz de distinguir até agora o quente do frio, o subjetivo do objetivo, o humano do não-humano (p. 33). ${ }^{6}$

A imagem comumente atribuída pelos alunos do Ensino Médio ao cientista como alguém solitário em seu laboratório ${ }^{16}$ destoou da noção apresentada pelos respondentes. Uma vez que optaram por uma carreira ligada diretamente à atividade científica, é possível que sua escolha estivesse pautada por uma concepção menos estigmatizada, com a presença de três atributos necessários que se destacam como comuns pelos quatro grupos: criatividade, competência e conhecimento. $\mathrm{O}$ atributo desnecessário, ser ateu, também recorrente em todos os grupos, completa as características genéricas de um pesquisador da área de Química, segundo o conjunto geral dos calouros.

\section{REFERÊNCIAS E NOTAS}

1. de Andrade, J. B.; Cadore, S.; Vieira, P. C.; Zucco, C.; Pinto, A. C.; Quim. Nova 2003, 26, 445.

2. de Andrade, J. B.; Cadore, S.; Vieira, P. C.; Zucco, C.; Pinto, A. C.; Quim. Nova 2004, 27, 358.

3. SBQ; Resumos da $26^{a}$ Reunião Anual da Sociedade Brasileira de Química, Águas de Lindoia, Brasil, 2003.

4. Araújo, M. H.; Lago, R. M.; Oliveira, L. C. A.; Cabral, P. R. M.; Cheng, L. C.; Borges, C.; Filion, L. J.; Quim. Nova 2005, 28, S26.

5. http://fm-sciences.org/, acessada em Abril 2009.

6. Latour, B.; A esperança de Pandora, EDUSC: Bauru, 2001.

7. "Transladar interesses significa, ao mesmo tempo, oferecer novas interpretações desses interesses e canalizar as pessoas para direções diferentes" (p. 194).

8. Nas três ênfases: licenciatura, industrial e bacharelado.

9. Strack, R.; Dissertação de Mestrado, Universidade Federal do Rio Grande do Sul, Brasil, 2010.

10. Strack, R.; Del Pino, J. C.; Anais do XIV Encontro Nacional de Ensino de Química, Curitiba, Brasil, 2008.

11. Embora não seja o foco deste trabalho remontar às origens destes entrelaçamentos, é interessante ressaltar que os interesses do mercado e os usos militares talvez remontem aos próprios primórdios do conhecimento cientifico moderno.

12. Silva, F. L. E.; Estudos Avançados 2001, 15, 295.

13. Stein, S.; MCRobbie, C.; Research in Science Education 1997, 24, 611.

14. Latour defende a ideia de uma ontologia enquanto processo, na qual o que, no idioma da modernidade ficou conhecido como uma dicotomia (sujeito-objeto), para este autor, são proposições que dão origem, por uma série de articulações e translações, a humanos e não humanos os quais, só remotamente e por concessões político-epistêmicas, coincidem, respectivamente, a sujeitos e objetos.

15. Latour, B.; A vida de laboratório, Relume-Dumará: Rio de Janeiro, 1997.

16. Kosminsky, L.; Giordan, M.; Química Nova na Escola 2002, n. 15, 11.

17. No sentido de uma concepção criacionista - descrita na Bíblia - da origem da Terra e da vida.

18. Souza, R. F.; Carvalho, M.; Matsuo, T.; Zaia, D. A. M.; Ciência Hoje 2009, 36, 256.

19. A iconoclastia aqui referida, como bem estilizado por Latour, se apresenta marcadamente, como o próprio nome sugere, a uma sanha de demolição dos ídolos pretensamente associados a uma crença ingênua.

20. No sentido de que o iconoclasta está sendo ingênuo ao considerar que o suposto crente crê ingenuamente.

21. Paiva, G. J. D.; Psicologia: Reflexão e Crítica 2002, 15, 561. 